\title{
MANAGEMENT OF GINGIVAL RECESSION USING LATERALLY REPOSITIONED FLAP-A CASE REPORT
}

Gaurav Arora, ${ }^{1}$ Vikram Blaggana, ${ }^{1}$ Preeti Upadhyay, ${ }^{1}$ Pragya Tripathi ${ }^{1}$

${ }^{1}$ Department of Periodontics, Inderprastha Dental College and Hospital, Sahibabad, Ghaziabad, Uttar Pradesh, India

\begin{abstract}
Correspondence address: Dr Gaurav Arora Senior Lecturer Department of Periodontics Inderprastha Dental College and Hospital, Sahibabad, Ghaziabad Uttar Pradesh, India Email: drgauravaroraa@gmail.com

\section{ABSTRACT} and patient was satisfied with case resolution.

Keywords: gingival recession, laterally repositioned flap

\section{INTRODUCTION}

Gingival recession is the apical shift of the gingiva from its normal position on the crown of the tooth to levels on the root surface beyond the cementoenamel junction. ${ }^{1}$ The laterally repositioned flap is used to cover denuded root surface that has adequate donor tissue laterally as well as adequate vestibular depth. Several factors account for this unpleasant and unaesthetic effect: trauma due to toothbrushing or other traumas on gingival tissue, lack of attached gingiva, gingival inflammation, local iatrogenic factors, anomalous insertions of bridles, altered tooth positioning, shallow vestibule, thin bone cortical plate or presence of bone fenestrations, and dehiscences. ${ }^{2}$ The presence of an alveolar bone dehiscence is considered a prerequisite for the development of a marginal tissue recession. ${ }^{3}$ There are several techniques available with the purpose of achieving the coverage of exposed root surfaces ${ }^{4}$ such as coronally reposition flap, subepithelial connective tissue grafts, and free gingival grafts.
\end{abstract}

Gingival recession is defined as apical migration of gingival margin in relation to cement enamel junction. The laterally repositioned flap is used to cover denuded root surface that has adequate donor tissue laterally as well as adequate vestibular depth. This article highlights the use of laterally repositioned flap for the management of localized Miller's Class II gingival recession. An excellent esthetic outcome was achieved

\section{CASE REPORT}

A 35 years old patient reported to the Department of Periodontics, Indraprastha Dental College \& Hospital with a chief complaint of receding gums in a lower front tooth. The recession was localized and was classified as Grade II according to Miller's Classification in tooth no. 31. The recession was $\sim 3 \mathrm{~mm}$ in depth and width of attached gingival was also found to be $3 \mathrm{~mm}$. Patient was medically fit and surgery was planned. Patient was informed about the procedure and after taking consent, scaling and root planning were performed.

\section{Surgical Procedure}

Local anesthesia (2\% lignocaine hydrochloride with 1: 80,000 adrenaline) was given. Recipient bed was prepared by removing marginal gingiva surrounding the tooth. Partial thickness flap was reflected from adjacent teeth, that is, 32 and 33. Root conditioning with tetracycline $\mathrm{HCl}$ was done on tooth no. 31 to allow biological attachment of the lateral graft. The graft was then adapted 
over the recipient site of tooth no. 31 with finger pressure using wet cotton. Interrupted resorbable sutures were then placed without tension followed by periodontal dressing. Postoperative instructions were given and antibiotics and analgesics were prescribed for 5 days to prevent postoperative swelling and pain. Patient was discharged and was recalled after 10 days.

There was uneventful healing of surgical site. Defect at donor site was healed by secondary intention. Patient was reviewed again after 3 months and no recurrence of gingival recession was observed.

\section{DISCUSSION}

Laterally positioned flap (LPF) is indicated to cover gingival recession of one or more teeth, allowing

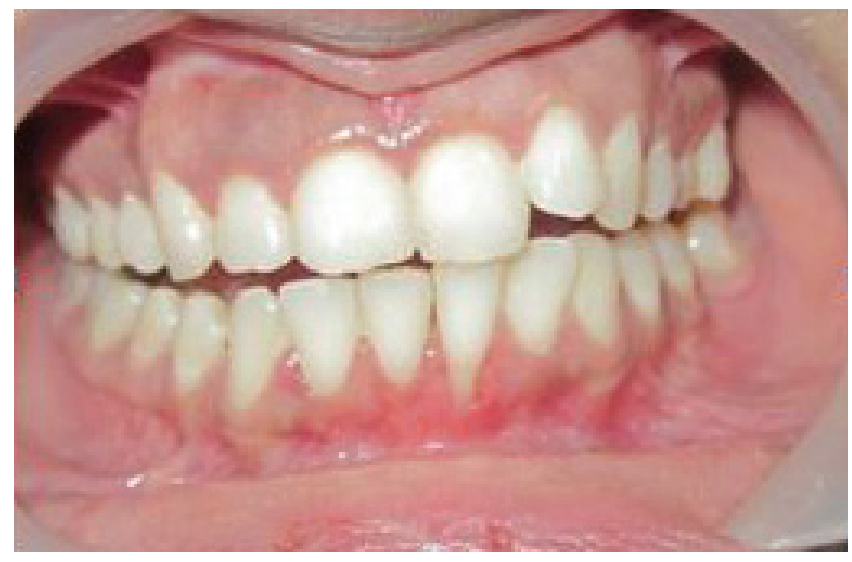

Figure 1: Preoperative view-Tooth 31.

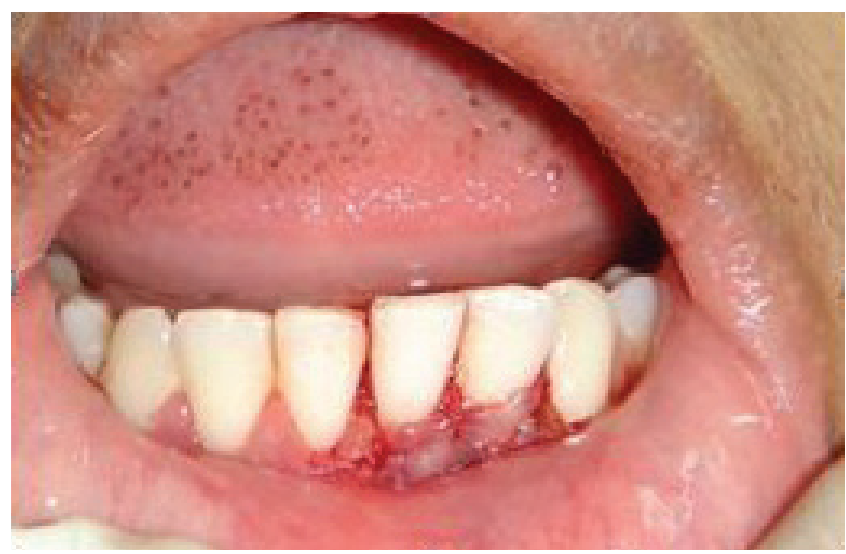

Figure 2: Adaptation of graft-Tooth 31. better aesthetic results, increasing width of attached gingiva and decreasing both hypersensitivity and cervical caries. This technique should never be used in the presence of interproximal periodontal pocket, areas of excessive root prominence, and places of excessive cervical abrasions. LPF was first described by Grupe and Warren ${ }^{5}$ as a surgical procedure comprising the use of full-thickness pedicle flap moved horizontally or laterally to cover the denuded root, which can consequently lead to the exposure of the donor area's bone tissue. Staffileno ${ }^{6}$ recommended the use of a partial-thickness pedicle flap, consequently maintaining the donor area covered by periosteum. The success of root coverage depends on many factors such as elimination of etiological factors, level of interproximal bone, and technique of root coverage. In this case report, laterally repositioned flap was used to cover recession defect as there was good periodontal support in neighboring tissues as well as normal bone height with good keratinized epithelium. The aim of this study was to report a clinical case of an isolated gingival recession in lower anterior region treated by laterally repositioned flap.

\section{CONCLUSION}

An excellent esthetic outcome and complete root coverage were achieved. Patient was completely satisfied with the results.

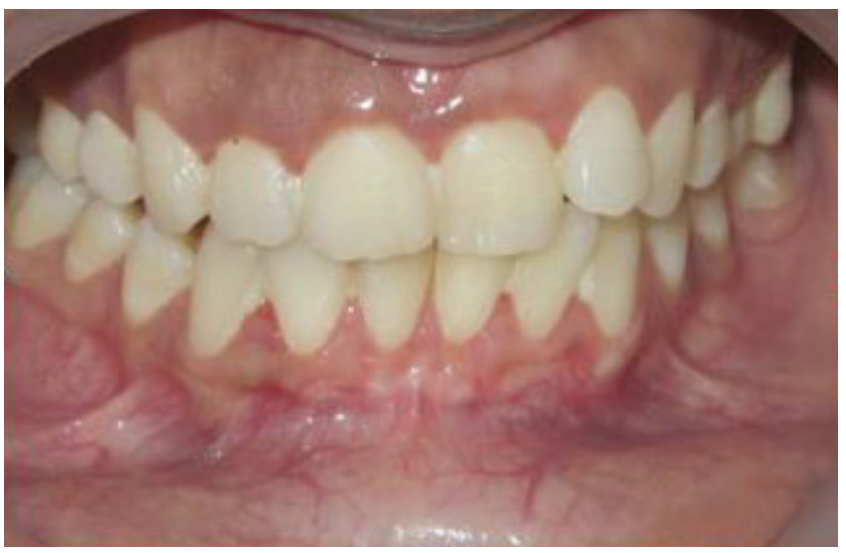

Figure 3: Three months postoperative view-Tooth 31. 


\section{REFERENCES}

1. Löe H, Anerud A, Boysen H. The natural history of periodontal disease in man: prevalence, severity, and extent of gingival recession. J Periodontol 1992;63(6):489-495

2. Glise JM, Monnet-Corti V. Periodontal surgical 'Envelope' technique for root coverage- subepithelial connective tissue graft: Case Reports.2002

3. Lindhe .Clinical Periodontology \& Oral Implantology; $4^{\text {th }}$ edition
4. Genco RJ, Cohen DW, Goldman HM. Contemporary Periodontium ; 1999

5. Grupe HE, Warren R. Repair of gingival defects by a sliding flap operation. J Periodontol 1956;27:92-95

6. Staffileno H. Management of gingival recession and root exposure problems associated with periodontal disease. Dent Clin North Am 1964;•••:111-120 